FINANCIAL: Jurnal Akuntansi

Published by Program Studi Akuntansi STIE Sultan Agung Volume 6-Nomor 2, Desember 2020, (HIm 145-153)

ISSN-P: 2502-4574, ISSN-E: 2686-2581

Available online at: https://financial.ac.id/index.php/financial

\title{
PERBANDINGAN PRAKTIK PEMBIAYAAN TABUNGAN SAFARI KOSPIN JASA SYARIAH BANJARAN TEGAL DENGAN FATWA DSN MUI NO. 02 TAHUN 2000
}

\author{
${ }^{1)}$ Nurul Wulandari Putri, ${ }^{2)}$ Dhiya Faras Febriani \\ ${ }^{1}$ STIE Syariah Putera Bangsa Tegal, Jalan Professor Muhammad Yamin No.22, Trayeman, Kudaile, \\ Kec. Slawi, Tegal, Jawa Tengah, 52413, Indonesia \\ ${ }^{2}$ Universitas Islam Indonesia, Jl. Kaliurang No.Km. 14,5, Krawitan, Umbulmartani, Kec. Ngemplak, \\ Kabupaten Sleman, Yogyakarta, 55584, Indonesia \\ Email: ${ }^{1}$ Nwulandariputri@gmail.com, ${ }^{2}$ dhiyafaras52@gmail.com
}

\begin{abstract}
Abstrak
Pada zaman dimana ekonomi yang sedang tidak menentu, perlu sekiranya setiap individu memiliki cadangan dana. Cadangan dana tersebut yang sangat mudah dilakukan oleh masyarakat dapat berbentuk tabungan. Dalam hal Kospin Jasa Syariah Capem Banjaran hadir untuk memberikan produk yang dibutukan oleh masyarakat salah satunya Tabungan Safari yang merupakan tabungan berjangka dengan wisata gratis. Tujuan dari penelitian ini yaiitu untuk mengetahui tingkat kepatuhan pada produk Tabungan Safari Kospin Jasa Syariah Capem Banjaran terhadap Fatwa DSN MUI No. 02/DSN-MUI/IV/2000 tentang Tabunga. Penelitian ini menggunakan metode kualitatif deskriptif. Hasil penelitian ini menunjukkan bahwa praktik pembiayaan Tabungan Safari di Kospin Jasa Syariah Capem Banjaran masih ada beberapa yang tidak sesuai dengan Fatwa DSN MUI. Perbandingan praktik dalam pembiayaan Tabungan Safari telah sesuai dengan Fatwa DSN MUI No.02/DSNMUI/IV/2000 tentang Tabungan, diantaranya nasabah bertindak sebagai shahibul mal dan bank sebagai mudharib, modal yang diiyatakan Kospin Jasa Syariah harus menjelaskan jumlahnya dan dalam bentuk tunai bukan piutang, pembagian keuntungan didapatkan harus dinyatakan dalam bentuk nisbah. Tetapi ada juga beberapa praktik yang tidak sesuai dengan Fatwa DSN MUI seperti bank dapat melakukan berbagai macam usaha tetapi praktiknya Kospin Jasa Syariah menggunakan dana tersebut sebagai dana outstanding, yang mana seharusnya Kospin Jasa Syariah dapat.
\end{abstract}

Kata Kunci: Tabungan Safari, Kepatuhan Syariah, DSN MUI

\section{COMPARISON PRACTICES OF FUNDING SAVINGS SAFARI KOSPIN SHARIA BANJARAN TEGAL SERVICES WITH FATWA DSN MUI NO. 02 OF 2000}

\begin{abstract}
Abstarct
In times where the economy that was not erratic, necessary if only each individual has a reserve fund. Reserve funds that are very easy to do by the public can be in the form of savings. In the case of Kospin Jasa Syariah Capem Banjaran is here to provide products that are needed by the community one of which is the Safari Savings, which is a term savings account with free tours. The aim of the research is to determine the level of compliance of the product Savings Safari Kospin Jasa Syariah Capem Banjaran against DSN MUI No.02/DSNMUI/IV/2000 regarding saving. This research uses descriptive qualitative methods. The results of this study shows that there are still some Safari Savings financing practices at Kospin Jasa Syariah Capem Banjaran that are not in accordance with the Fatwa DSN MUI. Comparison of practices in financing Savings Safari has been in accordance with the DSN MUI No.02/DSN-MUI/IV/2000 about savings, including customers act as shahibul malls and banks as mudharib, capital Kospin Jasa Syariah should explain the amount and in the form of cash instead of credit, distribution of profits found to be expressed in the form of a ratio. But there are also some practices that do not conform with the DSN MUI as banks can various kinds of businesses but practice Kospin Jasa Syariah using funds such as funds outstanding, that which should Kospin Jasa Syariah can.
\end{abstract}

Keywords: Savings Safari, Compliance syariah, DSN MUI

Article History: Received: 26 Okt 2020 Revised: 24 Nop 2020 Accepted: 28 Nop 2020 


\section{PENDAHULUAN}

Pesatnya perekonomian di Indonesia terkhusus ekonomi syariah menyebabkan banyaknya suatu lembaga keuangan perbankan maupun industri keuangan non bank yang sekarang sedang hadir di tengah-tengah masyarakat. Berkat berkembangnya ekonomi islam di Indonesia, semakin meningkat juga lembaga keuangan mikro berbasis syariah baik dalam jumlah maupun kinerja. Lembaga Keuangan Mikro Syariah di Indonesia memberikan gambaran bahwa Sistem dalam Ekonomi Islam dapat beradaptasi dengan baik dengan perekonomian konvensional (wiwoho, 2014).

Permasalahan kemiskinan menjadi isu utama dalam perekonomian, bukan hanya perekonomian untuk Indonesia tetapi juga untuk negara lain. Untuk meminimalkan resiko dalam kemiskinan, diperlukan Lembaga Keuangan Mikro Syariah yang sangat dibutuhkan oleh masyarakat. Koperasi adalah perkumpulan otonom dari orang-orang yang bergabung secara sukarela untuk memenuhi kebutuhan dan aspirasi ekonomi, sosial dan budaya mereka yang sama melalui perusahaan yang dimiliki dan diawasi secara demokratis (Rohmatul, 2018). Kospin jasa syariah memberikan berbagai produk yang dapat membantu kebutuhan masyarakat sekitar, salah satunya adalah produk tabungan Safari hal ini yang membedakan kospin jasa syariah dengan keuangan mikro syariah lainnya.

Produk Tabungan Safari (Sadar Manfaat Berkoperasi) adalah tabungan berjangka dengan menerapkan sistem bagi hasil dalam bentuk pariwisata dan Tabungan Safari memberikan keuntungan setiap bulannya kepada nasabah berupa Copyright (C) 2020, FINANCIAL: Jurnal Akuntansi hadiah sejumlah uang dan motor dengan akad menggunakan akad Mudharabah. Akad Mudharabah sendiri adalah bahwa nasabah bertindak sebagai shohibul mal dan bank sebagai mudharib. Jika terjadi kerugian dalam pelaksanaan pembiayaan tersebut maka bank akan bertanggungjawab atas kerugian yang mungkin saja terjadi (Muhammad, 2014).

Setiap produk yang ada di lembaga keuangan mikro syariah harus memiliki Dewan Pengawas Syariah (DPS) guna mengotrol apakah produk yang ada di lembaga tersebut telah memenuhi prinsipprinsip Islam. Sama halnya dengan produk tabungan safari, Dewan Pengawas Syariah (DPS) akan mengatur apakah pelaksanaan akad mudharabah telah sesuai dengan Fatwa MUI No. 02/DSN-MUI/IV/2000 tentang jenis jenis tabungan dan ketentuan umum terkait tabungan berdasarkan mudharabah.

Peneliti akan memberikan manfaat untuk berbagai sektor. Bagi Akademis, hasil penelitian ini akan menambah pengetahuan dan menambah referensi untuk mengkaji tingkat kepatuhan pada produk Tabungan Safari Kospin Jasa Syariah Capem Banjaran terhadap Fatwa MUI No. 02/DSN-MUI/IV/2000, serta dapat dijadikan masukan maupun saran untuk dapat memperbaiki tentang yang ada pada produk Tabungan Safari di Kospin Jasa Syariah Capem Banjaran.

Penelitian ini tidak terlepas dari hasil penelitian terdahulu yang pernah dilakukan dan dijadikan sebagai bahan kajian ataupun bahaan perbandingan. Bahan penelitian terdahulu yang akan dijadikan sebagai perbandingan tidak jauh dari topik yang akan diteliti yaitu kepatuhan dalam naskah akad tabungan 
Safari terhadap Fatwa DSN MUI No. 02/DSN-MUI/IV/2000.

Pertama, penelitian jurnal ini dilakukan oleh Ainin Ainiyah \& A Syifaul Qulub yang dilakukan pada tahun 2019 dengan judul "Kepatuhan Syariah (Sharia Compliance) Akad Mudharabah di BMT BIM". Penelitian ini bertujuan untuk mengetahui kepatuhan syariah dalam akad nudharabah yang ada di BMT Bina Insan Mandiri Rengel Tuban dinilai dari Fatwa DSN MUI. Metode penelitian yang digunakan adalah kualitatif. Hasil dari penjelasan yaitu bahwa produk pembiayaan mudharabah ini harusnya hanya diperuntukan bagi internal pengurus atau pegawai BMT BIM, karena potensi resiko dari pembiayaan mudharabah ini cukup besar tidak untuk kalangan masyarakat umum (Qulub, 2019)

Kedua, penelitian jurnal ini dilakukan oleh yang dilakukan pada tahun 2017 dengan judul "Kesesuaian Fatwa DSN MUI No. 7/DSN-MUI/IV/2000 Dalam Produk Pembiayaan Kepada Koperasi Untuk Anggota (PKPA) Di Bank Jatim Syariah Cabang Darmo Kota Surabaya". Penelitian ini dilakukan untuk tujuannya adalah mengetahui bagaimana terpenuhinya kepatuhan syariah pada akad mudharabah yang ada dalam produk pembiayaan dinilai dari Fatwa DSN MUI No. 07/DSN-MUI/IV/2000. Metode penelitian adalah kualitatif. Hasil dari penelitian bahwa Bank Jatim sudah menerapkan kepatuhan syariah yang ada didalam akad mudharabah pada produk pembiayaan kepada koperasi kepada anggota (PKPA) yang sesuai dengan Fatwa DSN MUI No. 7/DSNMUI/IV/2000 (Prasetyo, 2016).

Ketiga, penelitian jurnal ini dilakukan oleh Ade Sofyan Mulazid yang dilakukan pada tahun 2016 dengan judul "Pelaksanaan Sharia Compliance Pada Bank Syariah (Studi Kasus Pada Bank Syariah Mandiri, Jakarta)". Peneltian ini dilakukan dengan tujuan yaitu untuk mengentahui bagaimana sistem pengawasan terkait kepatuhan syariah di Bank Indonesia dan di Dewan Pengawas Syariah pada Bank Mandiri Syariah. Metode penelitian adalah kualitatif. Hasil penelitian menyatakan bahwa sistem pengawasan kepatuhan syariah yang dilakukan baik dari Bank Indonesia maupun DPS telah melakukan tugasnya sebagai pengawas telah baik. Kepatuhan syariah yang diterapkan oleh Bank Mandiri Syariah telah sesuai prinsip kepatuhan, budaya kepatuhn, manajemen resiko serta kode etika kepatuhan (Mulazid, 2016).

\section{LANDASAN TEORI}

\section{Konsep Kepatuhan Syariah}

Dalam konsep kepatuhan syariah, kepatuhan merupakan standar yang telah diatur suatu organisasi atau lembaga yang memiliki wewenang dalam bidang tersebut. Dan syariah menurut bahasa arab yaitu jalan yang harus diikuti. Sehingga kepatuhan syariah menurut Arifin, yaitu penerapan prinsip syariah dalam transaksi keuangan maupun perbankan ataupun bisnis lainnya (Arifin, 2009).

$$
\text { Kepatuhan syariah adalah }
$$
pemenuhan prinsip syariah dalam suatu lembaga yang terdapat karakteristik, intergritas serta kredibilitas dalam bank syariah, arti dari kepatuhan syariah secara operasional sendiri merupakan kepatuhan terhadap Fatwa DSN MUI karena fatwa DSN MUI sendiri merupakan poros dari prinsip serta aturan shari'ah yang harus ditaati oleh lembaga keuangan syariah 
baik perbankan syariah ataupun lembaga lainnya (Sutedi, 2009).

Kepatuhan syariah ini mencakup semua aspek yang ada di perbankan syariah, baik produk maupun transaksinya. Dalam kepatuhan syariah tidak hanya meliputi operasionalnya saja tetapi juga dalam sistem, teknik maupun identitas dari perusahaan tersebut (Indonesia, Peraturan Bank Indonesia Tentang Pelaksanaan Fungsi Kepatuhan Bank Umum, 2011). Pemegang kebijakan perbankan di Indonesia sendiri yaitu Bank Indonesia menjadikan Fatwa DSN MUI sebagai poros perbankan syariah. Yang artinya Bank Indonesia menjadikan Fatwa DSN MUI sebagai peraturan bagi Bank Indonesia dalam aspek kepatuhan syariah. Dalam hal ini Fatwa DSN MUI digunakan untuk menumbuhkan keseragaman norma daspek syariah dalam produk-produk yang ada dalam perbankan syariah.

\section{Ketentuan Kepatuhan Syariah}

Ketentuan ini digunakan untuk menilai tingkat kepatuhan syariah yang ada didalam lembaga keuangan syariah. Ketentuan ini meliputi 1) Akad yang akan digunakan dalam pengumpulan serta penyaluran dana sesuai dengan prinsip syariah dan aturan syariah yang ada, 2) Dana zakat akan dihitung, dibayar dan dikelola sesuai dengan prinsip syariah yang ada, 3) Seluruh transaksi serta aktivitas ekonomi yang dilakukan oleh Lembaga Keuangan Syariah akan dilaporkan sesuai dengan standar akuntasi syariah, 4) Lingkungan sesuai dengan prinsip-prinsip syariah, 5) Bisnis usaha yang akan dibiayai tidak melanggar prinsip-prinsip syariah, 6) Terdapat DPS sebagai penunjuk atas keseluruhan aktivitas operasional yang ada di lembaga keuangan syariah, dan 7) Sumber dana yang ada berasal dari sumber daya yang sah serta halal.

Ketentuan diatas adalah prinsip umum yang akan menjadi acuan bagi manajemen lembaga keuangan syariah dalam menjalankan suatu kegiatan yang ada di keuangan syariah. Kepatuhan syariah dalam keuangan syariah sendiri dinilai dari ketentuan-ketentuan tersebut untuk mengetahui apakah operasional dari keuangan syariah telah sesuai dengan ketentuan umum yang ada dalam kepatuhan syariah (Sutedi, 2009).

\section{Tabungan Mudharabah}

Tabungan merupakan simpanan dimana penarikannya dilakukan dengan syarat tertentu, dan penarikannya tidak dapat menggunakan cek, bilyat giro atau yang lainnya. Jika nasabah ingin menarik simpannya harus datang langsung ke bank denngan membawa buku tabungan, slip penarikan atau bisa juga menggunakan fasilitas ATM. Dan tabungan syariah merupakan simpanan yang menggunakan prinsip-prinsip syariah dalam ketentuannya (Anshori, 2009).

Mudharabah merupakan kata yag berasal dari kata dharb yang artinya memukul. Secara teknis, mudharabah merupakan akad kerja sama yang melibatkan beberapa pihak, pihak pertama yaitu shahibul mal (penyedia dana) dan mudharib (pengelola dana). Mudharabah menurut ahli fiqih adalah perjanjian dimana seseorang memberikan harta yang dimiliki kepada orang lain, dengan menggunakan prinisp dagang yang dimana keuntungan didapat akan dibagi berdasarkan pembagian yang telah disetujui saat awal akad (Simamora, 1990). 


\section{Rukun dan Syarat Mudharabah}

Rukun syarat dalam pembiayaan mudharabah menurut dengan Fatwa DSN MUI No: 07/DSN-MUI/IV/2000 pada ketetapan kedua yaitu: Pertama, Penyedia dana atau sahibul maal dan pengelola atau mudharib harus faham terkait hukum. Kedua, Dalam kontrak atau akad harus memperhatikan beberapa hal seperti penerimaan harus eksplisit, Penerimaan dari hasil penawaran yang ada dilakukan pada saat kontrak, dan Akad dituangkan secara tertulis. Ketiga, Modal yang diberikan dari penyedia dana kepada pengelola dana dalam menjalankan usahanya harus memiliki beberapa syarat, yaitu: Modal harus diketahui jumlah serta jenisnya, Modal dapat juga berbentuk uang ataupun barang, dan Modal yang diberikan tidak dapat berbentuk piutang. Keempat, Kegiatan usaha yang dilakukan dari pengelola dana (mudharib), harus memperhatikan hal sebagai berikut: Kegiatan usaha yang dilakukan oleh mudharib merupakan hak sepenuhnya bagi pengelola dana, Penyedia dana tidak dibolehkan mempersempit tindakan dari pengelola dana, dan Pengelola dana tidak dibenarkan menyalahi hukum syariah.

\section{Fatwa MUI No. 02/DSN-MUI/IV/2000}

Pada ketetapan pertama
menjelaskan mengenai jenis-jenis
tabungan, yaitu: Tabungan berdasarkan
pada perhitungan berbasis bunga,
Tabungan yang tidak syariah atau tabungan berbasis prinsip Mudharabah serta Wadiah.

Ketetapan kedua, berisi mengenai ketentuan umum tabungan berlandaskan akad Mudharabah yaitu: Dalam transaksi mudharabah nasabah sebagai pemilik dana dan bank bertindak sebagai pengelola dana, Sebagai pengelola bank dapat melakukan berbagai macam kegiatan usaha selama tidak bertentangan dengan prinsip syariah serta mengembangkannya, Modal harus dinyatakan jumlahnya dengan jelas serta modal harus dalam bentuk tunai, Pembagian laba dinyatakan kedalam bentuk nisbah serta tercantum dalam akad pembukuan, Bank sebagai pengelola dana menutup biaya operasional tabungan menggunakan laba keuntungan yang menjadi haknya, Bank tidak diperbolehkan untuk mengurangi laba keuntungan dari nasabah tanpa ada persetujuan dari yang bersangkutan.

\section{METODE}

Jenis penelitian ini menggunakan metode penelitian kualitatif deskritif dengan pendekatan analisis isi. Penelitian kualitatif merupakan metode penelitian naturalistic karena penelitiannya yang dilakukan pada kondisi dimana kondisi yang alamiah yang mana metode ini digunakan untuk meneliti pada kondisi obyek alamiah yang mana penulis sebagai instrumen kunci, teknik pengumpulan data bersifat induktif, dan hasil yang didapatkan dalam metode penelitian kualitatif ini lebih menekankan pada makna dari pada generalisasi (Sugiyono, 2013). Dalam hal ini, objek penelitian adalah nasabah Kospin Jasa Syariah Capem Banjaran dan pihak Kospin Jasa Syariah Capem Banjaran yang berlokasi di Jalan Raya Utara Adiwerna No. 06, Banjaran, Kalimati, Kecamatan Adiwerna, Kabupaten Tegal, Jawa Tengah.

Sumber data yang digunakan dalam penelitian ini adalah data primer serta data sekunder. Data primer merupakan data yang diperoleh dari hasil wawancara langsung terhadap sumbernya yaitu 
Kospin Jasa Syariah. Sedangkan data sekunder merupakan data dari sumber kedua yaitu referensi-referensi yang dapat menunjang penelitian ini seperti brosur dan data laporan perusahaan.

Metode pengumpulan data yang digunakan dalam penelitian ini adalah metode wawancara, digunakan untuk mengumpulkan data yang didapatkan dari Kospin Jasa Syariah kantor Capem Banjaran terkait penelitian yang secara mendalam. Narasumber dalam wawancara ini adalah karyawan bagian marketing, karyawan yang memegang produk tabungan safari dan nasabah produk tabungan safari serta studi kepustakaan digunakan untuk memperkuat teori yang berasal dari beberapa sumber ilmiah.

\section{HASIL DAN PEMBAHASAN}

\section{Analisis Akad Tabungan Safari Kospin Jasa Syariah Banjaran}

Tabungan Safari merupakan sebuah simpanan dengan sistem arisan yang menguntungkan dengan arisan tersebut akan dilakukan penyaringan setiap bulan, dan tabungan safari ini menggunakan akad Mudharabah. Salah satu kelebihan Tabungan Safari ini mengajak peserta untuk gathering dan berlibur ke tempat wisata bersama dengan peserta lainnya secara gratis. Periode dalam tabungan ini adalah 30 bulan, dengan setoran $\mathrm{Rp}$ 350.000,- per bulan, dan simpanan ini tidak dapat diambil sebelum jatuh tempo. Dalam hal ini Tabungan Safari membutuhkan rekening induk atau Takop sebagai rekening pendebetan otomatis yang akan memotong secara otomatis dana yang ada di rekening induk atau Takop untuk membayar angsuran dari Tabungan Safari.
Adapun fasislitas yang didapatkan dalam Tabungan Safari, yaitu: Aman, Memiliki rekening induk (Takop), Bebas biaya administrasi, Untuk peserta yang setor tabungan rutin berhak mengikuti wisata gratis, Untuk peserta yang tidak pernah menunggak selama 30 bulan berhak mendapatkan souvernir dari Kospin Jasa, Hadiah utama berupa uang yang akan diundi tiap bulan, Untuk peserta yang mendapatkan hadiah utama saat penyaringan hadiah utama maka kepesertaannya dalam Tabungan Safari gugur dam tidak perlu menyetor kembali, Untuk peserta yang tidak mendapatkan hadiah utama dan tidak ada tunggakan akan mendapatkan pencairan seluruh tabungan, dan Hadiah ekstra beurpa sepeda motor yang akan diundi di akhir periode.

Kospin Jasa Syariah Banjaran mempunyai berbagai jenis produk salah satunya yaitu Tabungan Safari adalah tabungan atau simpanan berjangka yang berakad Mudharabah Muthalqah, Tabungan Safari ini memberikan bagi hasil berupa wisata.

Menurut prinsipnya, akad Mudharabah yaitu bank sebagai mudharib akan mengelola dana dari nasabah atau penyedia dana yang dapat memperguakan dana sebagai usaha, yang nantinya akan mendapatkan hasil, dan hasil tersebut akan dibagi antara kedua belah pihak sesuai saat awal perjanjian.

Dari hasil wawancara dengan Bapak Lilik Kuniawan mengatakan bahwa: "Tabungan Safari ini merupakan tabungan berjangka dengan waktu tahun setengah yang menggunakan prinsip Mudharabah Muthlaqah. Dimana nasabah sebagai shahibul mal dan Kospin Jasa Syariah sebagai mudharib. Kospin Jasa Syariah akan memberikan wisata gratis kepada 
nasabah. Dengan biaya setoran sebesar Rp 350.000" (Kuniawan, 2020).

Dalam hal ini sesuai dengan pengaplikasian dari akad Mudharabah, dimana nasabah sebagai penyedia dana atau shahibul mal dan Kospin Jasa Syariah sebagai pengelola dana. Nantinya dari pengelola dana ini, Kospin Jasa Syariah akan memberikan bagi hasil berdasarkan dengan nisbah yang telah disepakati diawal perjanjan.

Dari hasil wawancara dengan Ibu Desi Nitasari dikatakan bahwa:"Tabungan Safari ini merupakan perjanjian antara dua pihak diantaranya yaitu Kospin Jasa Syariah sebagai pengelola dan nasabah sebagai penabung. Dalam pelaksanaanya, Kospin Jaaa Syariah bebas untuk mengelola dana tersebut dan nantinya akan memberikan bagi hasilnya kepada nasabah" (Nitasari, 2020).

Tabungan yang dibenarkan pada prinsipnya menggunakan akad wadiah dan mudharabah. Jika bank menggunakan akad Mudharabah Muthlaqah maka artinya bank akan bebas menggunakan dana yang diberikan oleh shahibul mal (nasabah), tanpa ada campur tangan dari nasabah. Dalam kegiatannya keuntungan yang didapatkan akan dibagi kedua belah pihak dan memiliki tenggang waktu dalam dana yang diberikan dan pembagain hasil usaha.

\section{Analisis Komparatif Akad Tabungan Safari dengan Fatwa DSN MUI No. 02/DSN-MUI/IV/2000}

Dalam Fatwa DSN MUI No. 02 tahun 2000 tentang mudharabah pada butir ke 2 nomor 1, menjelaskan mengenai "Nasabah bertindak sebagai shahibul mal dan bank sebagai mudharib". Nasabah melakukan akad dengan Kospin Jasa Syariah sebagai shahibul mal atau penyedia dana dan Kospin Jasa Syariah menjadi mudharibnya atau pengelola dana.

Tabungan Safari menggunakan akad Mudharabah muthlaqah maka ini sesuai juga dengan Fatwa DSN MUI No. 02 tahun 2000 pada butir 1 nomor 2 bahwa "Tabungan yang dibenarkan, yaitu tabungan berdasarkan prinsip mudharabah dan wadiah"

Kospin Jasa Syariah menetapkan dana yang diserahkan sebagai modal kepada nasabah berbentuk uang dan modal yang diserahkan naabah kepaada Kospin Jasa Syariah secara bertahap. Ini sesuai dengan Fatwa DSN MUI No. 02 tahun 2000 pada butir ke 2 nomor 3 bahwa "Modal harus dinyatakan dengan jumlahnya, dalam bentuk tunai dan bukan piutang"

Kospin Jasa Syariah telah menetapkan nominal nisbah dalam kontrak akad, nisbah yang dituangkan dalam akad berbentuk prosentase yaitu $0,05 \%$ bagi nasabah dan $99,5 \%$ bagi Kospin Jasa Syariah. Yang mana ini sesuai dengan Fatwa DSN MUI No. 02 tahun 2000 pada butir ke 2 nomor 4 bahwa "Pembagian keuntungan harus dinyatakan dalam bentuk nisbah dan dituangkan dalam akad pembukuan rekening"

Pada Fatwa DSN MUI No. 02 tahun 2000 tentang Tabungan pada butir ke 2 nomor 1 menjelaskan bahwa "Bank dapat melakukan berbagai macam usaha yang tidak bertentangan dengan prinsip syariah". Dari hasil wawancara yang didapat, bahwa Kospin Jasa Syariah menggunkan dana yang diberikan nasabah tetap ada di outstanding saldo kantor. Yang mana seharusnya Kospin Jasa Syariah dapat memutar dana tersebut untuk pengembangan dari usahanya. 


\section{SIMPULAN DAN SARAN}

Berdasarkan hasil penelitian yang telah dijelaskan, maka penulis dalam menyimpulkan beberapa hal sebagai berikut:

Perbandingan praktik dalam pembiayaan Tabungan Safari telah sesuai dengan Fatwa DSN MUI No. 02 tahun 2000 tentang Tabungan, diantaranya menyatakan bahwa nasabah bertindak sebagai penyedia dana dan bank sebagai pengelola dana, modal yang diiyatakan Kospin Jasa Syariah harus menjelaskan jumlahnya dan dalam bentuk tunai, pembagian keuntungan yag didapatkan harus dinyatakan dalam bentuk nisbah. Tetapi ada juga beberapa praktik yang tidak sesuai dengan Fatwa DSN MUI seperti bank dapat melakakuan berbagai macam usaha tetapi praktiknya Kospin Jasa Syariah menggunakan dana tersebut sebagai dana outstanding, yang mana seharusnya Kospin Jasa Syariah dapat.

Disarankan kepada Kospin Jasa Syariah agar dalam praktiknya dapat dievaluasi kembali dalam pembiayaan Tabungan Safari selama ini. Diharapkan Kospin Jasa Syariah dalam menjalankan praktiknya untuk kedepan bisa sesuai dengan apa yang ditetapkan dalam Fatwa DSN MUI. Sehingga reputasi yang didapatkan tetap terjaga dan nasabah yang menjadi anggota akan tetap setia pada Kospin Jasa Syariah terutama pada produk Tabungan Safari.

Dewan Pengawas Syariah yang ada di Kospin Jasa Syariah diharapkan dapat melakukan pengawasan pada produk maupun praktik yang dilakukan oleh Kospin Jasa Syariah agar tidak ada perbedaan antara pratik dan ketetapan dalam Fatwa DSN MUI.

\section{DAFTAR PUSTAKA}

Anshori, A. G. (2009). Perbankan Syariah Di Indonesia. Yogyakarta: UII Pers.

Arifin, Z. (2009). Dasar-Dasar Manajemen Bank Syariah. Tanggerang: Aztera.

Kuniawan, L. (2020, Maret 23). (D. F. Febriani, Pewawancara)

Muhammad. (2014). Teknik Bagi Hasil dan Margin Keuangan pada Bank Syariah. Yogyakarta: UII Pers.

Mulazid, A. S. (2016). Pelaksanaan Sharia Compliance Pada Bank Syariah (Studi Kasus Pada Bank Syariah Mandiri, Jakarta). jurnal kajian keislaman madania, 37.

Nitasari, D. (2020, Juli 09). (D. F. Febriani, Pewawancara)

Prasetyo, A. T. (2016). Kesesuaian Fatwa DSN MUI No. 7/DSNMUI/IV/2000 Dalam Produk Pembiayaan Kepada Koperasi Untuk Anggota (PKPA) Di Bank Jatim Syariah Cabang Darmo Kota Surabaya. Jurnal Ekonomi Syariah Teori dan Terapan Unair, 26.

Qulub, A. A. (2019). Kepatuhan Syariah (Sharia Compliance) Akad Mudharabah yang ada di BMT Bina Insan Mandiri Cabang Rengel Tuban dinilai dari Fatwa DSN MUI. Jurnal EkonomiSyariah Teori dan Terapan Unair, 880.

Rohmatul, S. (2018). Koperasi BMT: Teori, aplikasi dan inovasi. karanganyar: cv.inti media kommmunika.

Simamora, A. (1990). Sistem Perbankan Syaiah. Jakarta: PT RINEKA CIPTA.

Sugiyono. (2013). Metode Penelitian Pendidikan Pendekatan Kuantitatif, Kualitatif, dan $R \& D$. Bandung: Alfabeta.

Sutedi, A. (2009). Perbankan Syariah, Tinjauan dan Beberapa Segi Hukum. Jakarta: Ghalia Indonesia. 
wiwoho, J. (2014). peran lembaga keuangan bank dan lembaga keuangan bukan bank dalam memberikan distribusi keadilan bagi masyarakat. 87-97.

\section{PROFIL SINGKAT}

Nurul Wulandari Putri, lahir di Tegal pada tanggal 20 Maret 1994. Pendidikan S1 ditempuh di Universitas Islam Indonesia jurusan Ekonomi Islam pada tahun 2016. Dan melanjutkan ke jenjang lebih tinggi yaitu S2 di Universitas Islam Indonesia dengan jurusan Ekonomi Islam dan tamat pada tahun 2018. Pekerjaan sebagai Dosen STIES Putera Bangsa Tegal.

Dhiya Faras Febriani lahir di Tegal pada tanggal 28 Februari 1998. Pendidikan S1 ditempuh di Universitas Islam Indonesia jurusan Ekonomi Islam pada tahun tahun 2020. Status merupakan seorang mahasiswa 